\title{
Differences in Accessibility of Public Health Facilities in Hierarchical Municipalities and the Spatial Pattern Characteristics of Their Services in Doumen District, China
}

\author{
Dahao Zhang ${ }^{1}$ (D), Guojun Zhang ${ }^{2, *}$ and Chunshan Zhou ${ }^{1}$ (D) \\ 1 School of Geography and Planning, Sun Yat-sen University, No. 135, Xingang Xi Road, \\ Guangzhou 510275, China; zhangdh27@mail2.sysu.edu.cn (D.Z.); zhoucs@mail.sysu.edu.cn (C.Z.) \\ 2 School of Finance, Guangdong University of Finance and Economics, No. 21 Luntou Road, \\ Guangzhou 510320, China \\ * Correspondence: guojunz@gdufe.edu.cn
}

\section{check for} updates

Citation: Zhang, D.; Zhang, G.; Zhou, C. Differences in Accessibility of Public Health Facilities in Hierarchical Municipalities and the Spatial Pattern Characteristics of Their Services in Doumen District, China. Land 2021, 10, 1249. https:// doi.org/10.3390/land10111249

Academic Editors: Baojie He, Ayyoob Sharifi, Chi Feng and Jun Yang

Received: 19 September 2021 Accepted: 10 November 2021 Published: 14 November 2021

Publisher's Note: MDPI stays neutral with regard to jurisdictional claims in published maps and institutional affiliations.

Copyright: (c) 2021 by the authors. Licensee MDPI, Basel, Switzerland. This article is an open access article distributed under the terms and conditions of the Creative Commons Attribution (CC BY) license (https:/ / creativecommons.org/licenses/by/ $4.0 /)$.

\begin{abstract}
This study used the two-step floating catchment area method and potential model to calculate facility accessibility and potential service scope of public health infrastructure distribution, and to evaluate its spatial equity. We applied the Gini coefficient to measure the spatial equilibrium at each level of public health infrastructure in Doumen District, Guangdong, China, from different perspectives. The following results were obtained: (1) Significant spatial differences were observed in the accessibility of public health facilities among different levels; the higher the health facility level, the greater the difference in spatial accessibility. Spatial differences in the accessibility of public health infrastructure at the primary level and higher were distributed in a block-like pattern, while spatial differences in the accessibility of rural health stations were distributed in a circular pattern. Administrative villages tended to have the highest and lowest accessibility of tertiary and secondary hospitals, but not of primary hospitals and rural health stations. The frequencies for administrative villages with the highest and lowest accessibility were $32.8 \%$ and $49.6 \%$ of the total number of villages in the district, respectively, for tertiary hospitals; $39.2 \%$ and $48.8 \%$ for secondary hospitals; $19.2 \%$ and $24.8 \%$ for primary hospitals; $16.8 \%$ and $21.6 \%$ for rural health stations. (2) The potential service scope was spatially dissociative for tertiary hospitals, and differed more significantly in terms of space for secondary hospitals; the potential service scope of the two overlapped. The potential service scope of primary hospitals was relatively balanced, with strong spatial continuity, while that of rural health service centers was spatially fragmented. The service scope of rural health service centers was mostly consistent with their respective village-level administrative divisions. (3) The higher the level of public health infrastructure, the less balanced its spatial layout. Conversely, the lower the level of public health infrastructure, the more balanced its spatial layout.
\end{abstract}

Keywords: hierarchical municipalities; public health facilities; accessibility; Doumen District

\section{Introduction}

Public health infrastructure refers to medical institutions aimed at ensuring the health needs of the public and are compatible with social and economic development. International research on public health service facilities primarily focuses on four areas. (1) Hospitals' service quality and patients' satisfaction with medical services provided in health facilities, evaluated by performing structural equation modeling, computing correlation coefficients between hospital service quality and patients' willingness to pay, and assessing the effect of the management system of the medical facilities on service quality [1-3]. (2) The impact of the spatial layout of healthcare facilities on residents, including exploring its impact on the accessibility of public health services for rural residents in Australia through GIS. Previous results demonstrated the importance of analyzing residents' spatial choice of regional health facilities based on differences in education, regional 
poverty, and personal income. A need for comparative study of the temporal changes in the accessibility of public health services for residents from different geographic and political backgrounds, and an assessment of the impact of the spatial distribution of medical resources on that of residents' morbidity rate has been established [4-7]. (3) Analyses of differences in relevant indicators of medical institutions, including the spatial evaluation of greening in urban medical facilities, evaluation of the transport accessibility of urban medical facilities, and the spatial layout of hospital beds [8-12]. (4) The impact of the spatial layout of medical facilities on social economics, comprising an evaluation of the impact of spatial equity changes in medical institutions for public health expenditure between 2001 and 2013. Results highlighted the importance of a comparative analysis of variability factors in knowledge management between public and private hospitals [13-15]. Previous studies mainly employed structural equation modeling, the DEMATEL method, logistic regression, geographically weighted regression, and geographic information system.

Since the 19th National Congress, China has attached great importance to the degree of coverage provided by the social security system and the equal development of healthcare facilities for urban and rural residents. Statistics from the National Health Commission of the People's Republic of China reported that as of the end of August 2020, China had 35,000 hospitals, 967,000 primary medical and health institutions, and 16,000 specialized public health institutions. Compared with the end of August 2019, except for an increase in the number of private hospitals and community health service centers, the number of public hospitals, disease prevention and control centers, township health centers, and village health offices have all decreased in varying degrees [16]. The spatial equity of medical institutions is an important factor representing the balanced development of urban and rural residents' medical and health care. Due to a lack of scientific coordination in the spatial layout of various types of medical institutions, the imbalance in the quality of public health infrastructure in urban and rural areas is an important factor that results in inadequate access to medical care for residents in rural areas. Thus, it is especially important to explore the spatial layout and equity of multilevel public health service facilities based on the spatial scale at the village level.

Despite the significant urbanization of rural China, the lack of infrastructural development in rural areas has unbalanced the spatial layout of urban and rural medical and health resources. More attention has since been paid to the spatial layout characteristics of public health service facilities [17-20], demand and supply levels in urban medical resource services [21,22], and accessibility of medical service facilities [23-26].

To summarize, the current domestic and international research studies on public health services are mainly characterized by the service quality of and satisfaction with health facilities, the spatial layout and accessibility analysis of medical facilities, the demand and supply levels of medical resource services, the socioeconomic impact of the spatial layout of medical facilities, etc. Furthermore, studies on the spatial equity of public health infrastructure at different levels based on the village scale is relatively scarce [27-30]. Doumen District is located in the heart of the Guangdong-Hong Kong-Macao Greater Bay Area, and it is rapidly developing under the background of the dividend radiation and policy assistance of said area. The rural population of Doumen District is the highest among all the districts of Zhuhai City; the balanced allocation of its medical and health resources is not only conducive to adapting to the needs of urban development planning of the Guangdong-Hong Kong-Macao Greater Bay Area, but also to the establishment of a medical and health service system that is worthy of an internationally inhabitable city. Even if municipal districts of China-the core components of cities and regional development centers-are generally highly urbanized and densely populated, those in regions in the process of urban development (as Doumen District) are dominated by subdistricts and townships, with an urban-rural dual structure characterizing its public health infrastructure. In view of this, the present study used the Doumen District of Zhuhai City as an example, the townships as the research unit, and combined the two-step floating catchment area (2SFCA) method with a potential model and Gini coefficient to evaluate the spatial equity 
of public health service facilities at different levels, based on population density. GIS technology for visualization analysis was also used; this is important for promoting spatial equity of multilevel public health service facilities and for the efficient use of regional medical resources. GIS also provides useful references for enhancing the empiricism and rationality of the spatial layout of public health service facilities, ultimately improving the equal development of healthcare facilities, and the quality of regional human settlement environments [31-34].

\section{Methods}

\subsection{Overview of the Study Area}

The Doumen District is in the west of Zhuhai City in China's Guangdong Province, and it is rapidly developing under the background of the dividend radiation and policy assistance of Guangdong-Hong Kong-Macao Greater Bay Area. As of the end of 2019, the population of Doumen District was 521,700, with a hospital bed capacity of 4.01 per 1000 people (Figure 1). The problem of insufficient medical and health resources, overall, is becoming increasingly prominent, and the demands of residents' medical and health services cannot be fully met. The layout of medical and health institutions in district and towns (subdistricts) is unbalanced, with $61.08 \%$ of beds and the most large-scale medical equipment concentrated in the district-level hospitals. Concurrent to the further deepening of hierarchical diagnosis and treatment, the problem of insufficient resources for primary medical and health institutions has been increasingly aggravated.

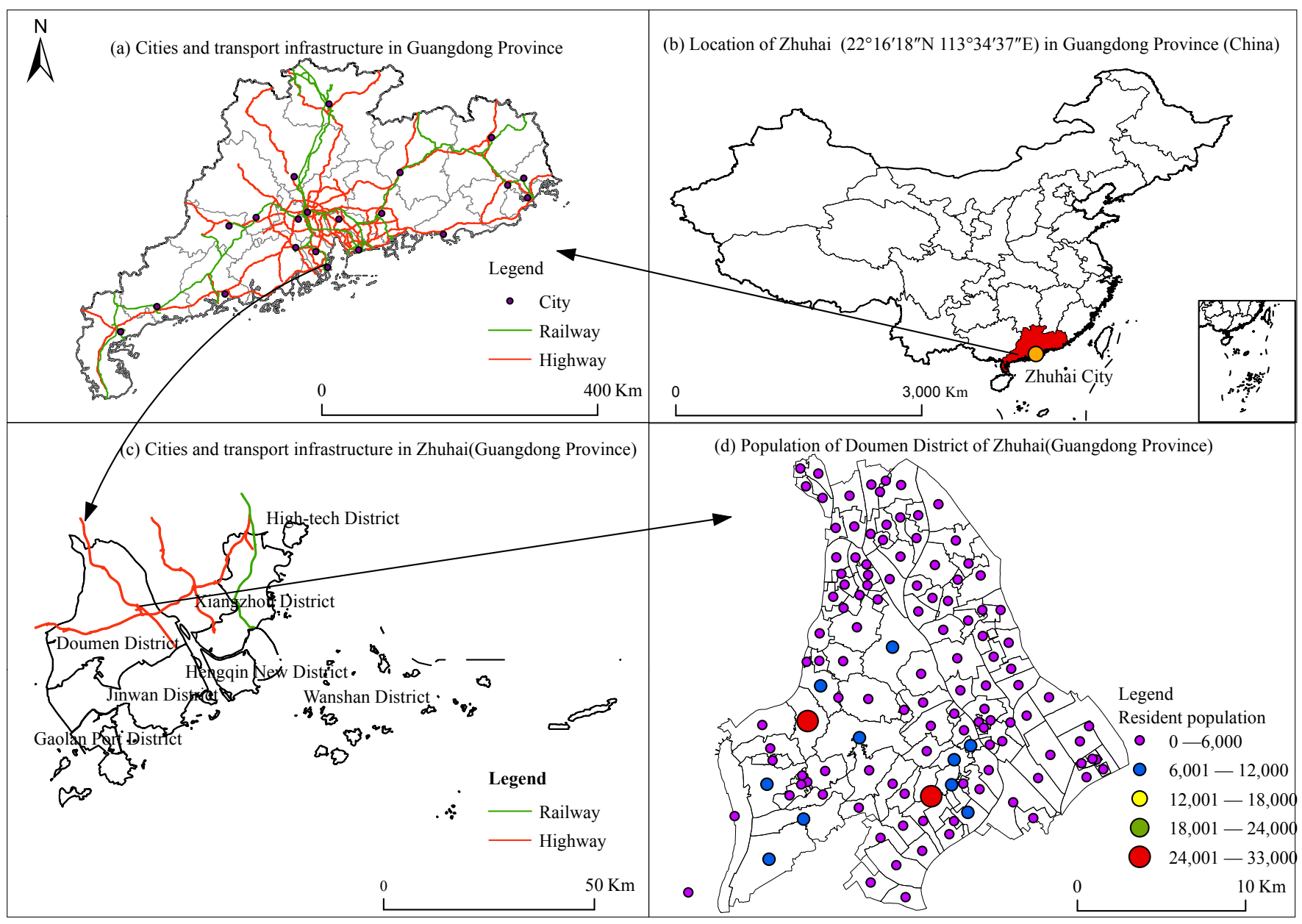

Figure 1. The geographic distribution of the study area. (a) Cities and transport infrastructure in Guangdong Province. (b) Location of Zhuhai in Guangdong Province (China). (c) Cities and transport infrastructure in Zhuhai (Guangdong Province). (d) Population of Doumen District of Zhuhai (Guangdong Province). 


\subsection{Data Sources}

This study primarily included data on the public health infrastructure in Doumen District, such as the location of hospitals and the number of beds in each hospital. The public health infrastructure in Doumen District mainly included two tertiary hospitals, four secondary hospitals, eight primary hospitals, and ninety-eight rural health service centers with a four-level health service system. These data were derived from the statistical reports of district-level medical and health service facilities in 2020. Village-level population data mainly indicated the resident and household population data of each residential committee and administrative village of the entire district, which was derived from the seventh population census data of Doumen District. Geospatial coordinate data comprised the latitudinal and longitudinal coordinates of the administrative village sites and public health service facilities obtained from the Baidu map coordinate picking system (http:/ / aqsc.shmh.gov.cn/gis/getpoint.htm; Figure 2) (accessed on 16 June 2020). This study also included other basic data that comprised administrative division data, obtained from the Resources and Environment Science and Data Center of the Chinese Academy of Sciences(http:/ / www.resdc.cn/data.aspx?DATAID=333; Table 1) (accessed on 8 June 2019).

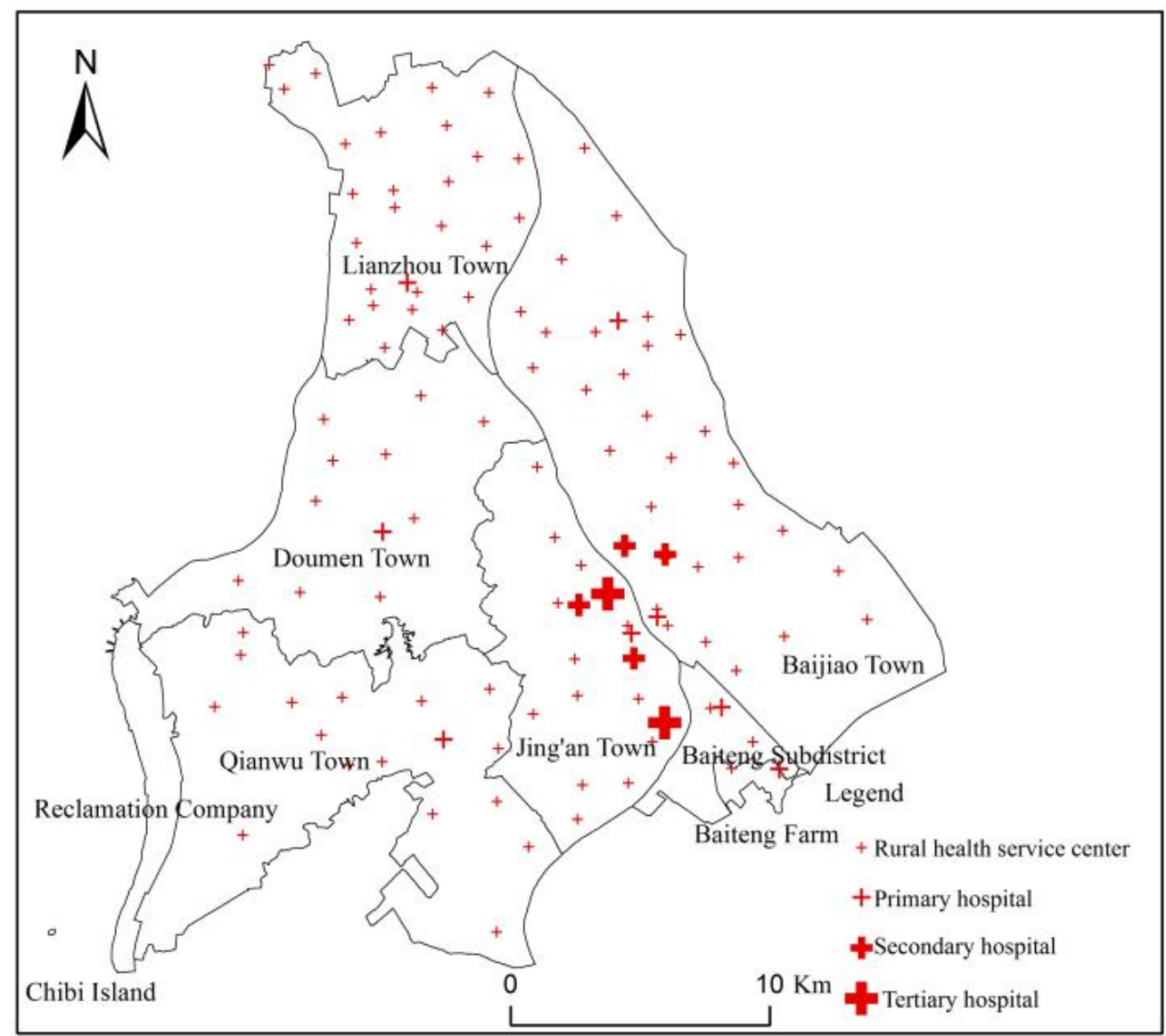

Figure 2. Spatial layout of multilevel medical facilities in Doumen District of Zhuhai (Guangdong Province). China, 2020. 
Table 1. Data sources and descriptions.

\begin{tabular}{|c|c|c|c|c|}
\hline Data Category & Data Description & Data & Data Source & Reference Year \\
\hline $\begin{array}{l}\text { Public medical } \\
\text { facility data }\end{array}$ & $\begin{array}{c}\text { Hospital name, } \\
\text { location, number of } \\
\text { beds, etc. }\end{array}$ & Panel data & $\begin{array}{l}\text { Statistical reports on } \\
\text { medical and health } \\
\text { service facilities }\end{array}$ & 2020 \\
\hline Population data & $\begin{array}{c}\text { Permanent population } \\
\text { and migrant } \\
\text { population }\end{array}$ & Panel data & $\begin{array}{l}\text { The seventh population } \\
\text { census data }\end{array}$ & 2020 \\
\hline Traffic network data & Highways and railways & Vector data & Baidu map & 2019 \\
\hline $\begin{array}{l}\text { Medical facility spatial } \\
\text { coordinate data }\end{array}$ & $\begin{array}{l}\text { Medical facility latitude } \\
\text { and longitude }\end{array}$ & Vector & $\begin{array}{l}\text { Baidu map coordinate } \\
\text { pickup system } \\
\text { Resources and }\end{array}$ & 2020 \\
\hline $\begin{array}{l}\text { Administrative } \\
\text { division data }\end{array}$ & $\begin{array}{l}\text { Administrative } \\
\text { boundary }\end{array}$ & Vector data & $\begin{array}{c}\text { Environment Science } \\
\text { and Data Center of the } \\
\text { Chinese Academy } \\
\text { of Sciences }\end{array}$ & 2019 \\
\hline
\end{tabular}

\subsection{Research Methodology}

\subsubsection{Two-Step Floating Catchment Area Method}

The two-step floating catchment area method was first proposed by Radke and $\mathrm{Mu}$ in 2000 [35]. It is a unique gravity model that overcomes the defects of the previous floating catchment area method. In accordance with the method name, two steps are taken to evaluate the accessibility to public health facilities based on the demand and supply [36]. The spatial accessibility of hospitals of $r(=1,2,3,4)$ level in Doumen District was calculated by the two-step floating catchment area as follows:

In the first step, all demand points $(k)$ are searched within the distance threshold $\left(\mathrm{d}_{0}\right)$ from the r-level supply point $j_{r}$. Then, the supply-demand ratio $R_{j r}$ is calculated:

$$
R_{j r}=\sum_{k \in D_{j r}} \frac{S_{j r}}{P_{k}}, r=1,2,3,4 .
$$

Here, $D_{j r}$ is the subset of the $\mathrm{k}$ demand points, with distance from the r-level supplier point $j_{r}$ less than or equal to $d_{0}, P_{k}$ is the demand for public health facilities, and $S_{j r}$ is the number of beds.

In the second step, the supply point $\left(j_{r}\right)$ within the threshold range $\left(d_{0}\right)$ are searched from each demand point $\mathrm{k}$. Then, the supply-demand ratios $\left(R_{j r}\right)$ of all the supply points are added to obtain the $A^{F}{ }_{k}$ of demand point $k$ :

$$
A_{k}^{F}=\sum_{j r \in \sum_{j r}} R_{j r}, r=1,2,3,4 .
$$

Here, the symbol SIGMA ${ }_{j r}$ is the subset of the $j_{r}$ r-level supplier points, with distance to demand node $k$ less than or equal to $d_{0}$ distance. $A^{F}{ }_{k}$ is the sum of supply-demand ratios within the range of the demand point $k$; a large value indicates better accessibility and vice versa. The accessibility of different levels of medical facilities was classified into five levels: highest, high, moderate, low, and lowest by using the Jenks Natural Breaks method in ArcGIS [37].

First, the linear distance between settlements and public health infrastructure was less than $10 \mathrm{~km}$ by calculating the shortest distance between the site and the site of supply, generating the OD cost matrix and setting the threshold of the search range to $10 \mathrm{~km}$. Second, the total service population within the search scope of each public health infrastructure, and the supply-demand ratio of public facilities corresponding to each settlement, were calculated. Third, the supply and demand ratio of public facilities within the search scope of the residential area was summarized. Finally, the residential information was linked to the summary of the supply and demand ratio of public facilities within the residential 
search scope. The spatial accessibility of Doumen hospitals at different levels was measured by the two-step mobile search method.

\subsubsection{Potential Model}

The potential model, also known as the gravity model, uses the physical law of gravitation in geography and regional economics to describe the spatial interactions of socioeconomic activities; the potential represents the strength of spatial interactions produced by one object on another.

$$
C_{i}=\sum_{j=1}^{n} A_{i j}=\sum_{j=1}^{n} \frac{M_{j}}{D_{i j}^{\beta}}
$$

In the above equation: $A_{i j}$ denotes the potential generated by object $j$ on object $i$, when the travel friction coefficient is $\beta ; M_{j}$ denotes the activity scale at point $j ; D^{\beta} i j$ denotes the travel impedance factor from point $i$ to point $j$ when the travel friction coefficient is $\beta ; C_{i}$ denotes the set of potential generated by all objects in the system at point $i$, that is, the spatial service scope of public health facilities.

First, the OD matrix between settlements and public health services was calculated. Second, the impedance coefficient was set to 2. In their review of Love, Berens et al. and Brimber, Peeters et al. found that they had mainly concentrated on a coefficient range of $[0.9,2.29]$, although it has little impact between $[1.5,2]$. We study the two cases, $\beta=1$ and $\beta=2$, separately, through comparison. We suppose the study results were more reasonable at selecting 2 by comparing the results of calculation [38]. The potential probability of each public health service facility being selected by a resident was calculated using the potential energy between the residential site and the public health service facilities. The public health service facility with the maximum corresponding potential value for each resident was screened. Finally, the potential scope of services for each public health service facility was summarized.

\subsubsection{Gini Coefficient}

The Gini coefficient was used to measure the equilibrium of the spatial distribution of a facility in a region, according to the Lorentz curve, which can reflect the differential characteristics of the spatial layout of public health infrastructure at different levels. The location Gini coefficient was used to calculate the spatial differentiation characteristics of public health infrastructure at different levels in Doumen District. We used the following formula:

$$
G=\frac{\sum_{j}^{N} \sum_{i}^{N}\left|S_{i}-S_{j}\right|}{2 N^{2} \bar{S}}
$$

where $G$ is the location Gini coefficient, $N$ is the total number of regions, $S$ is the average number of hospitals in each region, $i$ and $j$ each represent a different region, $S_{i}$ and $S_{j}$ indicate the number of hospitals at one level in regions $i$ and $j$, respectively, for the total number of hospitals in the whole study area. The location Gini coefficient is [0,1], if the Gini coefficient is 0 , the distribution of the level is completely balanced in the study area, the closer the location Gini coefficient is to 1, the more uneven the distribution in the study area, and the level is completely concentrated in one area.

\section{Results}

The spatial accessibility of different levels of hospitals in Doumen District was calculated by the two-step floating catchment area (2SFCA) method, and the accessibility of different levels of medical facilities was classified into five levels: highest, high, moderate, low, and lowest by using the Jenks Natural Breaks method in ArcGIS. Figure 3 depicts that the spatial differentiation characteristics of accessibility of public health facilities at all levels in Doumen District were significant, where the degree of spatial differences in accessibility was significantly higher in tertiary hospitals than in secondary hospitals, primary hospitals, and rural health stations. 
The potential model was used to divide the spatial service scope of individual hospitals at different levels in Doumen District (Table 2). The colored blocks reflect the overlapping potential service ranges of public health service facilities (Figure 4).

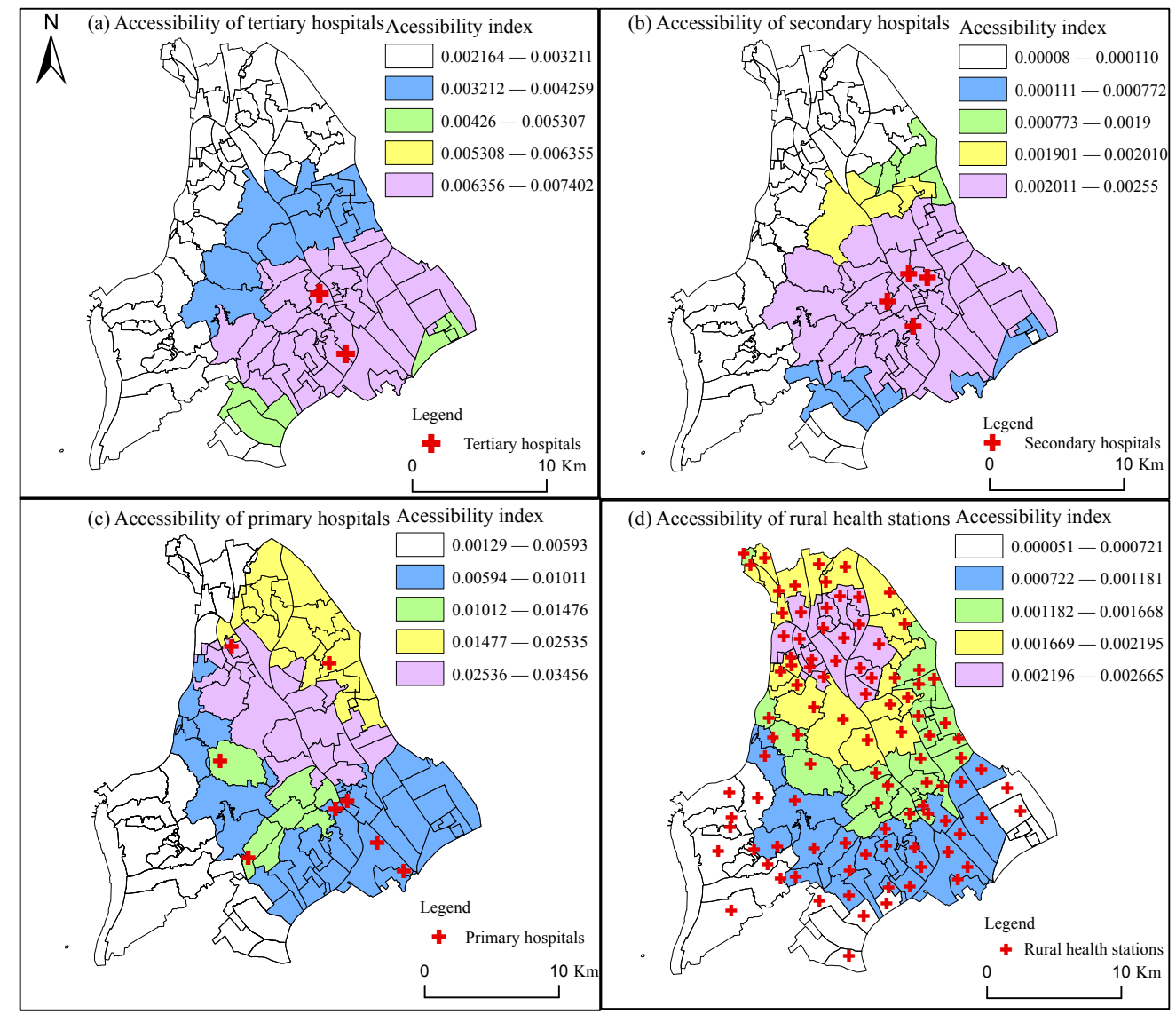

Figure 3. Spatial accessibility layout of public health facilities in the Doumen District of Zhuhai (Guangdong Province), China, 2020. (a) Accessibility of tertiary hospitals. (b) Accessibility of secondary hospitals. (c) Accessibility of primary hospitals. (d) Accessibility of rural health station.

Table 2. Hospitals by service level. Doumen District of Zhuhai (Guangdong Province), China, 2020.

\begin{tabular}{|c|c|c|}
\hline Level & Number of Beds $\left(S_{j r}\right)$ & Facility Code \\
\hline Tertiary hospital & 1500 & \\
\hline Affiliated Hospital of Zunyi Medical University, Zhuhai & 1000 & 0 \\
\hline Zhuhai Jiuming Geriatric Hospital & 500 & 1 \\
\hline Secondary hospital & 569 & \\
\hline Qiaoli Hospital of Traditional Chinese Medicine & 399 & 0 \\
\hline Doumen District Maternal Child Health Hospital (Baijiao) & 25 & 1 \\
\hline Doumen District Maternal and Child Health Hospital (Jingan) & 25 & 2 \\
\hline Zhuhai Fang Hua Hospital & 120 & 3 \\
\hline Primary hospital & 523 & \\
\hline Jingan Town Health Center & 37 & 0 \\
\hline Baijiao Town Health Center & 50 & 1 \\
\hline Doumen Town Central Health Center & 80 & 2 \\
\hline Qianwu Town Central Health Center & 30 & 3 \\
\hline Lianzhou Town Central Health Center & 36 & 4 \\
\hline Baiteng Subdistrict Central Health Center & 0 & 5 \\
\hline Zhuhai Ci'ai Rehabilitation Hospital & 200 & 6 \\
\hline Zhuhai Tonghe Hospital & 90 & 7 \\
\hline Rural * & 286 & \\
\hline
\end{tabular}

* There are $n$ rural facilities in Doumen District. 


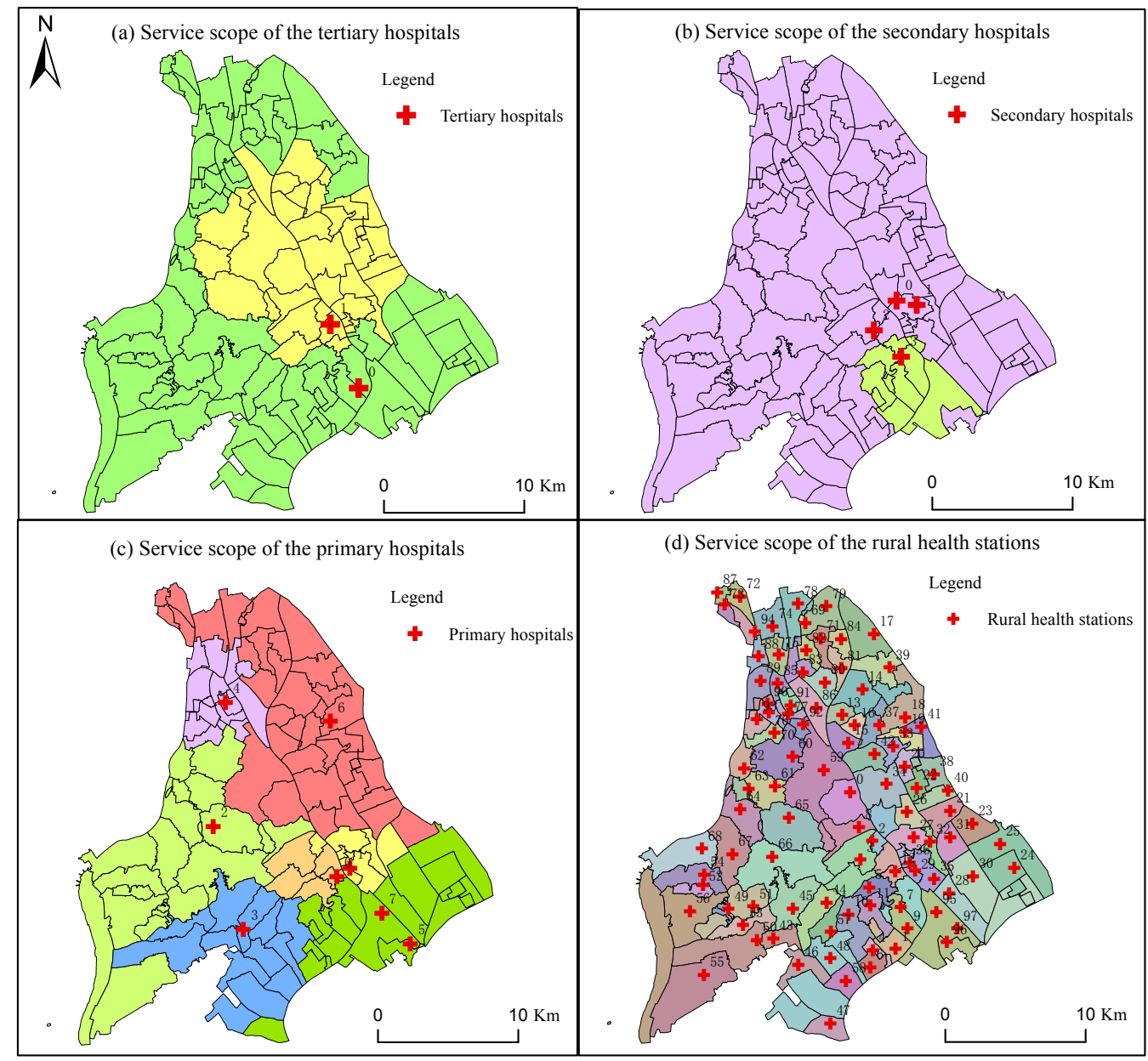

Figure 4. Zoning map of the service scope of multilevel public health facilities in Doumen District, of Zhuhai (Guangdong Province), China, 2020. (a) Service scope of the tertiary hospitals. (b) Service scope of the secondary hospitals. (c) Service scope of the primary hospitals. (d) Service scope of the rural health stations.

The permanent population density and migrant population density of Doumen District was calculated using the inverse distance weighting method (Figure 5). In terms of spatial layout, the permanent population density was higher in the southwest and south of Doumen District, and lower in the southeast, central, and north. The migrant population was mainly concentrated in the southwest of Doumen District, with scattered density in the south, and low density in the southeast and north. The spatial equity of multilevel public health service facilities was evaluated by combining the permanent and migrant population density, the spatial accessibility of public health service facilities, and the spatial service scope of Doumen District [39]. The spatial equilibrium of the different public health service facilities in Doumen was measured by the Gini coefficient (Table 3). 
Table 3. Gini coefficient table of multi-level public health facilities in Doumen District of Zhuhai (Guangdong Province), China, 2020.

\begin{tabular}{ccccc}
\hline & $\begin{array}{c}\text { Tertiary } \\
\text { Hospitals }\end{array}$ & $\begin{array}{c}\text { Secondary } \\
\text { Hospitals }\end{array}$ & $\begin{array}{c}\text { Primary } \\
\text { Hospitals }\end{array}$ & $\begin{array}{c}\text { Rural Health } \\
\text { Stations }\end{array}$ \\
\hline Jingan Town & 0.031 & 0.063 & 0.063 & 0.015 \\
Baijiao Town & 0 & 0.028 & 0.028 & 0.007 \\
Doumen Town & 0 & 0 & 0.045 & 0.045 \\
Lianzhou Town & 0 & 0 & 0.037 & 0.008 \\
Qianwu Town & 0 & 0 & 0.053 & 0.008 \\
Baiteng Sub-district & 0 & 0 & 0 & 0.125 \\
\hline
\end{tabular}

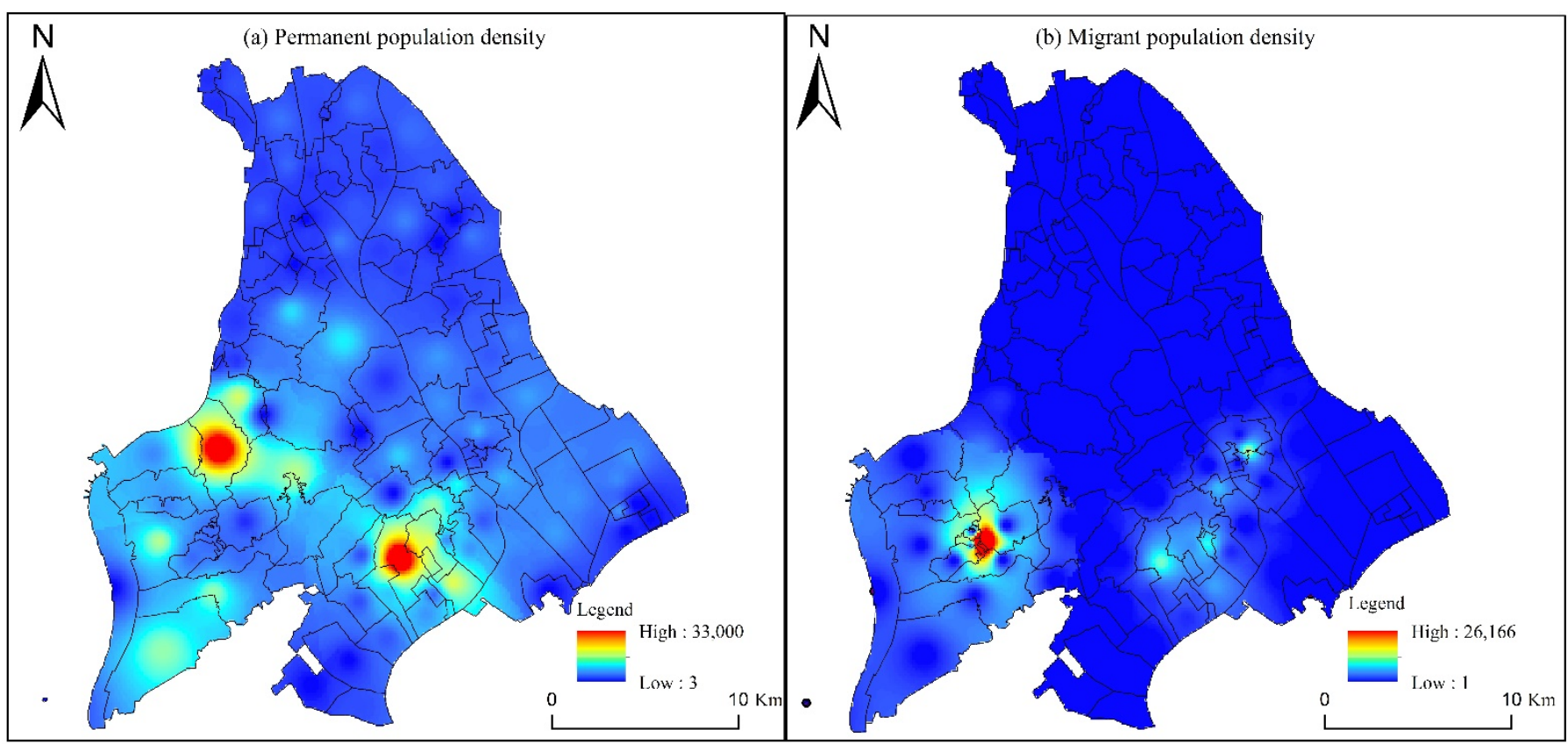

Figure 5. Spatial layout of permanent population density and migrant population density in Doumen District of Zhuhai (Guangdong Province), China, 2020. (a) Permanent population density. (b) Migrant population density.

\subsection{Tertiary Hospitals: Two, Jingan Town, 1500 Beds}

\subsubsection{Spatial Accessibility}

Due to the small number of tertiary hospitals (2), and their distribution in the central and southern towns, these areas have higher access to tertiary hospitals. The farther from the central and southern areas, the lower the accessibility of tertiary hospitals. The areas with the highest accessibility index (0.0064-0.0074) for tertiary hospitals were chiefly concentrated in the southeast of Doumen District, and the coverage area comprised 41 village-level administrative units-mainly distributed in the Baiteng Subdistrict and Baijiao Town, the south-central part of Jingan Town and the eastern part of Qianwu Town-accounting for $32.8 \%$ of the total number of village-level administrative units in the district. The areas with moderate accessibility index (0.0043-0.0052) were distributed in the southeast and southern parts of Doumen District, and the coverage area comprised 7 village-level administrative units-mainly distributed in the Baijiao Town and the southern parts of Qianwu Town-accounting for $5.6 \%$ of the total number of villages in the district. The areas with low accessibility index (0.0032-0.0042) were primarily distributed in the central part of Doumen District, and the coverage area consisted of 15 village-level administrative units-predominantly distributed in the central part of Baijiao Town, the northern part of Jingan Town, and the eastern part of Doumen Town-accounting for $12 \%$ of the total number of villages in the district. The areas with the lowest accessibility index $(0.0022-0.0031)$ were principally concentrated in the northern and western parts of Doumen 
District, and the coverage area comprised 62 village-level administrative units-chiefly distributed in the Lianzhou Town, the northern part of Baijiao Town, and the western parts of both Doumen Town and Qianwu Town-accounting for $49.6 \%$ of the total number of village-level administrative units in the district.

\subsubsection{Potential Service Space Scope}

The potential service scope of the tertiary hospitals was spatially discrete. The service scope of Zhuhai Jiuming Geriatric Hospital was relatively small and concentrated and mainly included the central part of Doumen District, which was the intersection area of the Doumen, Lianzhou, Jingan, and Baijiao Towns. The service scope of the Affiliated Hospital of Zunyi Medical University in Zhuhai was large and discrete and extended to the areas north and south of Doumen District.

\subsubsection{Spatial Equity}

Spatial differences in the accessibility of tertiary hospitals were the most significant; the accessibility of tertiary hospitals was high in the densely permanent-populated area in the south, and low in the densely permanent-populated area in the southwestern and northern parts of Doumen District. The densely migrant-populated areas in the southwest have low access to tertiary hospitals, while the south is characterized by sub-high density of migrant population areas and higher accessibility of tertiary hospitals. The service scope was spatially discrete; hence, the spatial equity of tertiary hospitals was the lowest. The Gini coefficient shows that, because the only two tertiary hospitals in Doumen District are both located in Jingan Town, and other towns have no tertiary hospitals, the spatial balance of tertiary hospitals is the worst in Jingan Town (0.031).

\subsection{Secondary Hospitals: Four, Jingan Town and Baijiao Town, 569 Beds}

\subsubsection{Spatial Accessibility}

The spatial distribution of secondary hospitals is relatively concentrated, mainly concentrated in the neighboring Jingan Town and central Baijiao Town. Therefore, the central of Jingan Town and Baijiao Town and its adjacent areas have high accessibility to secondary hospitals. The farther away from Jingan Town and central Baijiao Town, the lower the accessibility of secondary hospitals. Because the spatial layout characteristics of the secondary and primary hospitals have some convergence, they have similar spatial accessibility ranges. The areas with the highest accessibility index $(0.0021-0.0025)$ for secondary hospitals were chiefly concentrated in the southeastern and central parts of Doumen District, and the coverage area comprised 44 village-level administrative units-mainly distributed in the Jingan Town, the south-central part of Baijiao Town, the northeastern part of Qianwu Town, the southeastern part of Doumen Town, and the northern part of Baiteng Subdistrict-accounting for $35.2 \%$ of the total number of village-level administrative units in the district. The areas with high accessibility index (0.0019-0.0020) were distributed in the central parts of Doumen Town, and the coverage area comprised 5 village-level administrative units-predominantly distributed in the northern part of Baijiao Town and the northeastern part of Doumen Town-accounting for $4 \%$ of the total number of villages in the district. The areas with moderate accessibility index (0.0008-0.0018) were distributed in the northeastern part of Doumen District, and the coverage area comprised 5 village-level administrative units-mainly distributed in the northern of Baijiao Town-accounting for $4 \%$ of the total number of villages in the district. The areas with low accessibility index (0.0002-0.0007) were distributed in the southern part of Doumen District, and the coverage area comprised 10 village-level administrative units-predominantly distributed in the southern parts of Baijiao Town, Jingan Town, Qianwu Town, and Baiteng Subdistrictaccounting for $12.5 \%$ of the total number of villages in the district. The areas with lowest accessibility index (0-0.0001) were distributed in the western and northern of Doumen District, and the coverage area comprised 61 village-level administrative units-mainly 
distributed in the northern part of Baijiao Town, the western parts of Doumen, Qianwu, and Lianzhou Towns-accounting for $48.8 \%$ of the total number of villages in the district.

\subsubsection{Potential Service Space Scope}

The spatial variability of the service scope of the secondary hospitals was significant. Zhuhai Fang Hua Hospital had a small service scope, mainly including the Baiteng Subdistrict and the southeast of Jingan Town. The service scope of the Qiaoli Hospital of Traditional Chinese Medicine in Doumen District of Zhuhai City was larger, and it included most areas of Baijiao, Doumen, Lianzhou, Qianwu, and Jingan Towns. As the medical facilities of the Doumen District Maternal and Child Health Hospital (Baijiao) and the Doumen District Maternal and Child Health Hospital (Jingan) of Zhuhai City were relatively small, and they were close to the Qiaoli Hospital of Traditional Chinese Medicine, their service scope were covered by the Qiaoli Hospital of Traditional Chinese Medicine.

\subsubsection{Spatial Equity}

The accessibility of secondary hospitals was spatially characterized as "high in the east and low in the west." The accessibility of secondary hospitals was higher in the densely permanent-populated areas in the south and low in the densely permanent-populated areas in the southwestern and northern parts of Doumen District. The accessibility of secondary hospitals in the southwest was also low for the migrant population, while the southern sub-high density had higher accessibility of secondary hospitals for the migrant population. Although its service scope showed spatial continuity, the variability of service spatial scope zoning was significant, and the service scope of different hospitals appeared to overlap; therefore, the spatial equity of secondary hospitals was poor. The secondary hospitals in Doumen District are mainly distributed in Jingan Town and Baijiao Town. The spatial equilibrium coefficient of the secondary hospitals in Jingan Town and Baijiao Town is 0.063 and 0.028 , respectively. The degree of spatial equilibrium among secondary hospitals in Baijiao Town is better than that of Jingan Town.

\subsection{Primary Hospitals: Eight, All Towns, 523 Beds}

3.3.1. Spatial Accessibility

Because primary hospitals are mostly town-level health centers, they are distributed among all townships. Affected by administrative divisions, the spatial layout of primary hospitals is relatively scattered. Different from the spatial accessibility of tertiary and secondary hospitals, the areas with high accessibility of primary hospitals are not relatively concentrated around the primary hospitals, but rather the areas adjacent to Doumen Town, Lianzhou Town, Baijiao Town, and Jingan Town. The areas with the highest accessibility index (0.0254-0.0346) for primary hospitals were chiefly concentrated in the northern and central parts of Doumen District, and the coverage area comprised 24 village-level administrative units - mainly distributed in the northern part of Doumen Town and central parts of Baijiao and Jingan Towns-accounting for $19.2 \%$ of the total number of village-level administrative units in the district. The areas with high accessibility index (0.0148-0.0253) were distributed in the northeastern parts of Doumen District, and the coverage area comprised 22 village-level administrative units-predominantly distributed in the northern and western part of Baijiao and Lianzhou Towns, respectively-accounting for $17.6 \%$ of the total number of village-level administrative units in the district. The areas with moderate accessibility index (0.0102-0.0147) were distributed in the southeastern and central part of Doumen District, and the coverage area comprised 7 village-level administrative unitsmainly distributed in the central, eastern, and northeastern parts of the Jingan Town, Doumen, and Qianwu Towns, respectively-accounting for 5.6\% of the total number of villages in the district. The areas with low accessibility index (0.0060-0.0101) were distributed in the southeastern and western parts of Doumen District, and the coverage area comprised 41 village-level administrative units-predominantly distributed in the northern and southeastern parts of Doumen Town, the northeastern part of Qianwu Town, 
and the southern parts of Baijiao Town, Jingan Town, and Baiteng District-accounting for $32.8 \%$ of the total number of villages in the district. The areas with lowest accessibility index (0.0013-0.0059) were distributed in the northwestern and southwestern parts of Doumen District, and the coverage area comprised 31 village-level administrative units-mainly distributed in the western part of Lianzhou Town, the southwestern part of Doumen Town, and the western and southern parts of Qianwu Town-accounting for $24.8 \%$ of the total number of villages in the district.

\subsubsection{Potential Service Space Scope}

The primary hospitals were mainly the health centers in each township, and their service scope was relatively balanced and had strong spatial continuity. Among them, Jingan Town Health Center, Baijhao Town Health Center, Lianzhou Town Health Center, Qianwu Town Health Center, and Baiteng Subdistrict Community Health Center had smaller service scopes, which failed to cover their respective administrative areas. Doumen Town Central Health Center, Zhuhai Ci'ai Rehabilitation Hospital, and Zhuhai Tonghe Hospital had larger service scope and mitigated the problem of insufficient service coverage of the health centers in Jingan Town, Baijiao Town, Lianzhou Town, Qianwu Town, and Baiteng Subdistrict.

\subsubsection{Spatial Equity}

The spatial accessibility of the primary hospitals was characterized by a trend of high in the east and north, and low in the west and south. The service scope of Doumen Town Center Health Center, Qianwu Town Health Center, Baiteng Subdistrict Community Health Center, and Zhuhai Ci'ai Rehabilitation Hospital was larger than their own service capacity, and thus resulted in lower accessibility to primary hospitals in the densely permanentand migrant-populated areas, and the southern densely permanent-populated areas and sub-high migrant population density areas. However, the spatial layout of the primary hospitals was more balanced from the perspective of the service scope of public health facilities. The primary hospitals of Doumen District are mainly concentrated in Jingan Town, Baijiao Town, Doumen Town, Lianzhou Town, and Qianyuan Town, with spatial equilibrium coefficients of $0.063,0.0 .028,0.045,0.037$, and 0.053 , respectively. It is possible to show that the Baijiao Town has the best primary hospitals, with those in Lianzhou Town and Doumen Town second best; Qianwu Town and Jingan Town have the worst primary hospitals.

3.4. Rural Health Stations: Ninety-Eight, High in the North and Low in the South, Most Villages, 286 Beds

\subsubsection{Spatial Accessibility}

Rural health stations are mainly distributed at village-level unit, and they have the most balanced spatial layout. Because the administrative area is relatively narrow in the north, the spatial area of the village-level unit is generally smaller in the north than the south. The spatial distribution of northern rural health stations is relatively concentrated, so the northern area of Doumen area for rural health station accessibility is higher than the south Doumen area. The areas with the highest accessibility index (0.0022-0.0026) for rural health stations were chiefly concentrated in the northern part of Doumen District, and the coverage area comprised 21 village-level administrative units-mainly distributed in the southern and central parts of Lianzhou Town and the northwestern part of Baijiao Town-accounting for $16.8 \%$ of the total number of village-level administrative units in the district. The area with high accessibility index (0.0017-0.0021) were distributed in the central and northern parts of Doumen District, and the coverage area comprised 23 village-level administrative units-predominantly distributed in the northern parts of Doumen, Jingan, and Lianzhou Towns and the central and northern parts of Baijiao Town-accounting for $18.4 \%$ of the total number of village-level administrative units in the district. The areas with moderate accessibility index $(0.0012-0.0016)$ were distributed 
in the southern and central parts of Doumen District, and the coverage area comprised 27 village-level administrative units-mainly distributed in the northern part of Jingan and Doumen Towns and the central and northern parts of Baijiao Town-accounting for $21.6 \%$ of the total number of villages in the district. The areas with low accessibility index $(0.0008-0.0011)$ were distributed in the southern part of Doumen District, and the coverage area comprised 27 village-level administrative units-predominantly distributed in the central and southern parts of Doumen Town, the western part of Qianwu Town, and the southern parts of Jingan Town and Baijiao Town-accounting for $21.6 \%$ of the total number of villages in the district. The areas with lowest accessibility index (0.0001-0.0007) were distributed in the northwestern and southwestern parts of Doumen District, and the coverage area comprised 27 village-level administrative units-mainly distributed in the southwestern part of Doumen Town, the western and southern parts of Qianwu Town, and the southeastern part of Baijiao Town-accounting for $21.6 \%$ of the total number of villages in the district.

\subsubsection{Potential Service Space Scope}

The service scope of the rural health service centers showed a fragmented spatial distribution, except for the $10 \%$ of rural health service centers whose service scope contained 2-4 village-level administrative units; the remaining $90 \%$ of rural health service centers demonstrated a high consistency of service scope with their respective village-level administrative divisions.

\subsubsection{Spatial Equity}

The accessibility of rural health service centers was spatially characterized as "high in the north and low in the south." As the area of the northern part of Doumen District and the total area of village-level administrative divisions in the northern part were generally smaller than that of the southern part, the accessibility of the northern part was relatively high, while the accessibility of rural health service centers in the densely permanent- and migrant-populated areas in the southwest and south, and sub-high migrant population density areas was lower. In terms of public health facility service zoning, the service scope of most rural health service centers was consistent with the administrative divisions in which they were located, and the individual rural health service centers whose service scope included multiple village-level administrative units were mostly distributed in the southern part of Doumen District. Thus, the overall spatial layout of the rural health service centers in Doumen District was more balanced; however, the spatial layout of rural health service centers in the northern region was more balanced than that in the southern region. Rural health stations are distributed in towns, with the best spatial balance in Baijiao Town (0.007), Lianzhou Town (0.008) and Qianwu Town (0.008), Jingan Town (0.015) and Doumen Town (0.045), and the Baitenghu Subdistrict's Rural Health Service Center (0.125).

\section{Discussion}

\subsection{Study Innovations and Significance}

This paper combines the two-step floating catchment area method and the potential model to explore the accessibility of multi-level public health infrastructure and its potential spatial service scope and evaluates the spatial equity of public health service facilities. The current findings are of great significance to promote the spatial equalization of multi-level public health service facilities and the efficient utilization of regional land resources.

Compared to the existing research findings from China and other countries, this study offers the following novel implications: (1) Innovative research perspective-previous studies used a single perspective (i.e., accessibility) to evaluate the spatial equilibrium of facilities; however, this study employed a comprehensive evaluation method using the three perspectives of accessibility, potential spatial service scope, and population density [40-42]. (2) Most existing studies have evaluated the spatial equity of public health facilities using an overall dimension of spatial equity, which can only show the 
spatial balance of public health facilities. However, this study compared and analyzed the spatial equity of public health facilities at different levels, which can show the spatial balance of public health facilities as well as the spatial equity of the quality of public health facilities [43-46].

\subsection{Main Findings}

Based on the data on public health infrastructure and village-level population, the two-step floating catchment area (2SFCA) method, potential model, and Gini coefficient were used to explore the spatial accessibility of multilevel public health facilities in Doumen District, along with their potential spatial service scope. The spatial accessibility of public health service facilities was also evaluated. The conclusions of the analysis are as follows:

(1) The spatial differences in the accessibility between the levels of public health facilities in Doumen District were relatively significant: the higher the level of health facilities, the greater the spatial differences in their accessibility. In terms of the spatial accessibility of tertiary hospitals, the accessibility of the southeastern part of Doumen District was relatively high, while the accessibility of the western and northern parts was relatively low. In terms of spatial accessibility of secondary hospitals, the accessibility of the southeastern and central parts of Doumen District was relatively high, while the accessibility of the western and northern parts was relatively low. The spatial accessibility layout of secondary and primary hospitals was somewhat similar. From the viewpoint of the spatial accessibility of primary hospitals, the accessibility was higher in the central and northern parts of Doumen District, and lower in the western and southern parts. The northern part of Doumen District had the highest accessibility to rural health stations, and its accessibility was spatially distributed in a circular pattern from north to south. There are some similarities and differences between the findings of the current study and previous studies. The similarity lies in the relatively high accessibility of high-level and large-scale health service facilities. The difference lies in the suggestion by relevant studies of public health facilities that the level of health facilities is negatively correlated with the spatial difference of their accessibility, i.e., the higher the level of health facilities, the smaller the spatial difference of their accessibility; however, this study suggests that the level of health facilities is positively correlated with the spatial difference of their accessibility, i.e., the higher the level of health facilities, the greater the spatial difference of their accessibility [47-49].

(2) The potential service scope of tertiary hospitals in Doumen District was spatially discrete, while that of secondary hospitals had the most significant spatial differences, and primary hospitals reported a potential service scope which was relatively balanced and had strong spatial continuity. The service scope of rural health service centers was spatially scattered, and the service scope of most rural health service centers was consistent with the scope of their respective, village-level, administrative divisions. Recent domestic and foreign studies predominantly evaluate the overall spatial equity of public health facilities but lack a comparative analysis of the spatial equity of public health facilities at different levels to show the spatial equity of public health facilities and their quality [50-52].

(3) The spatial equity of public health service facilities at different levels was evaluated based on the perspectives of population density, spatial accessibility of facilities, and potential spatial service scope. The spatial equity of tertiary hospitals in Doumen District was the lowest, followed by secondary hospitals. Moreover, the spatial layout of primary hospitals was relatively balanced, while the overall spatial layout of rural health service centers was the most balanced, with those in the northern region being more balanced than those in the southern region.

\subsection{Countermeasure Suggestions}

(1) Among the tertiary hospitals, the number of beds in the Zhuhai Jiuming Geriatrics Hospital should be increased to broaden the scope of its medical services to the north. Among the secondary hospitals, the Maternal and Child Health Hospital of Doumen 
District, Zhuhai (Baijiao and Jingan) should be relocated and expanded to prevent its service scope from being addressed by the Qiaoli Hospital of Traditional Chinese Medicine. The number of beds in the primary hospitals should be increased in Jingan Town Health Center, Baijiao Town Health Center, Lianzhou Town Health Center, Qianwu Town Health Center, and Baiteng Subdistrict Community Health Center to expand their service scope. Rural health service centers should be in accordance with the four unified principles of construction-planning, design, identification, and standards-to achieve the allocation of one health center per village.

(2) The development planning and quality improvement of private medical institutions should be strengthened. The approval of social healthcare settings should be liberalized, support for social medical care should be increased, and the "15-min medical circle" should be established. Private institutions should be allowed to independently choose their own operating procedure as per their own circumstances to ensure fairness between private and public hospitals in terms of designated access to medical insurance and the 120-emergency medical network, title promotion, teaching and research, and policy knowledge. This will accelerate the formation of a diversified spatial layout of public health facilities and meet the multilevel and diversified medical service needs of residents.

\subsection{Outlook}

This study explored the accessibility and potential spatial service scope of regional public health service facilities and evaluated the spatial equity of public health service facilities. However, this study also had the following limitations: (1) The findings may have been influenced by personal biases and medical treatment preferences, and some residents may not opt for public health facilities within the spatial service scope but choose distant health facilities with higher service quality. (2) Existing longitudinal studies on health facility equity are lacking due to the insignificant long-term changes observed. Therefore, subsequent studies should account for residents' personal biases and medical treatment preferences through questionnaires and gather longitudinal healthcare service data to further explore the equity of public health service facilities and characteristics of their spatial and temporal evolution.

Author Contributions: Conceptualization, C.Z. and D.Z.; methodology, D.Z.; software, D.Z.; validation, C.Z. and G.Z.; formal analysis, C.Z.; data curation, D.Z; writing-original draft preparation, G.Z. and D.Z.; writing-review and editing, C.Z. and G.Z.; visualization, G.Z.; supervision, C.Z.; project administration, G.Z.; funding acquisition, G.Z. All authors have read and agreed to the published version of the manuscript.

Funding: This research was funded by the National Natural Science Foundation of China (On study of the Space-time Evolution of Digital Inclusive Finance in Urban Agglomerations and its Influence Mechanism on High-Quality Economic Development-Taking the Pearl River Delta Urban Agglomeration as an Example), grant number 42171188.

Institutional Review Board Statement: Not applicable.

Informed Consent Statement: Not applicable.

Data Availability Statement: Not Applicable.

Conflicts of Interest: The authors declare no conflict of interest.

\section{References}

1. Rafi, T.; Khalique, M.; Siddiqui, S.H. Hospital Service Quality and Patient Satisfaction: A Moderating Role of Trustworthiness. A J. Account. Financ. Emerg. Econ. 2020, 6, 237-250. [CrossRef]

2. Ghasem, Z.; Hajieh, G.A. The Role of Hospital Service Quality and Informing System in Patients' Willingness to Pay with Mediation of Satisfaction. Q. J. Manag. Strateg. Health Syst. 2020, 5, 112-118. [CrossRef]

3. Jagannath, R.; Krishnedu, A.; Samarjit, K.; Dragan, P. A rough strength relational DEMATEL model for analyzing the key success factors of hospital service quality. Decis. Mak. Appl. Manag. Eng. 2018, 1, 121-142. [CrossRef]

4. Matthew, R.M.; John, S.H. Spatial access disparities to primary health care in rural and remote Australia. Geospat. Health 2015, 10, 358. [CrossRef] 
5. Omotoso, O. Spatial Distribution and Provision of Rural Medical Services in Ekiti State, Nigeria. Afr. Res. Rev. 2009, 3, 40-53. [CrossRef]

6. Towne, S.D., Jr. Socioeconomic, Geospatial, and Geopolitical Disparities in Access to Health Care in the US 2011-2015. Int. J. Environ. Res. Public Health 2017, 14, 573. [CrossRef] [PubMed]

7. Ruth, K.; Pierre, G.; Ben, I.; Casey, T. Spatial Analysis of Lung Cancer Mortality in the American West to Improve Allocation of Medical Resources. Appl. Spat. Anal. Policy 2020, 13, 823-850. [CrossRef]

8. Brandy, J.M.; Mara, Z.V.; Elizabeth, G.; Robert, J.; Margaret, C.C.; Janet, A.T. Process Evaluation of a Community Garden at an Urban Outpatient Clinic. J. Community Health 2017, 42, 639-648. [CrossRef]

9. Byeongsun, K. Exploring emergency area for medical service using microscopic traffic simulation model. Spat. Inf. Res. 2016, 24, 75-84. [CrossRef]

10. Raj, P.; Marc, T.; Estie, K. Understanding the role of the public transport network in the greater Sydney area in providing access to dental care. Aust. Health Rev. 2018, 43, 628-635. [CrossRef]

11. Shawky, M. Spatial analysis of public health facilities in Riyadh Governorate, Saudi Arabia: A GIS-based study to assess geographic variations of service provision and accessibility. Geo-Spat. Inf. Sci. 2016, 19, 26-38. [CrossRef]

12. Jay, P.; David, S. Geographic distribution of hospital beds throughout China: A county-level econometric analysis. Int. J. Equity Health 2016, 15, 179. [CrossRef]

13. Samantha, B.M.; Sue, B.; John, G.; Paul, H.; Darlene, M.; Lillian, M.; Campbell, T.; Paul, R.W. Quantitative analysis of bariatric procedure trends 2001-13 in South Australia: Implications for equity in access and public healthcare expenditure. Aust. Health Rev. 2015, 39, 63-69. [CrossRef]

14. Hosung, S.; Eunsuk, A. Does the regional deprivation impact the spatial accessibility to dental care services? PLoS ONE 2018, 13, e0203640. [CrossRef]

15. Jawad, K.; Tong, S.; Naveed, A.; Sana, A.; Shahbaz, K.; Kashif, M. Promoting Healthcare Sustainability in Developing Countries: Analysis of Knowledge Management Drivers in Public and Private Hospitals of Pakistan. Int. J. Environ. Res. Public Health 2019, 16, 508. [CrossRef]

16. National Health Commission of the People's Republic of China. Available online: http://www.nhc.gov.cn/wjw/index.shtml (accessed on 6 June 2021).

17. Song, X.Q.; Wei, Y.P.; Deng, W.; Zhang, S.Y.; Zhou, P.; Liu, Y.; Wan, J.J. Spatio-Temporal Distribution, Spillover Effects and Influences of China's Two Levels of Public Healthcare Resources. Int. J. Environ. Res. Public Health 2019, 16, 582. [CrossRef] [PubMed]

18. Zhang, Y.L.; Li, W.X.; Deng, H.P.; Li, Y. Evaluation of Public Transport-Based Accessibility to Health Facilities considering Spatial Heterogeneity. J. Adv. Trans. 2020, 2020, 7645153. [CrossRef]

19. Liu, Q.; Li, C.G.; Shen, Q.X.; Zhang, J.; Ma, Z.P.; Zhou, G.L. Spatial Evolution Character of Medical Facilities in Changchun City. Econ. Geogr. 2017, 37, 139-145. [CrossRef]

20. Lu, T.; Wang, Y.; Meng, Q.; Yan, J.J. Large-scale Emergency Medical and Health Facilities Planning in Response to Public Health Emergencies. Planners 2020, 5, 89-93.

21. Duan, J.L.; Jiao, F.; Zhang, Q.S.; Lin, Z.B. Predicting Urban Medical Services Demand in China: An Improved Grey Markov Chain Model by Taylor Approximation. Int. J. Environ. Res. Public Health 2017, 14, 833. [CrossRef] [PubMed]

22. Ma, Z.F.; Yin, S.G.; Qiao, W.Y.; Li, Z.J.; Wu, Q.Y. Spatial Equilibrium State and Its Time Evolution of Medical Health Resource Supply Level in China. Sci. Geogr. Sin. 2018, 38, 869-876. [CrossRef]

23. Zheng, Z.C.; Xia, H.M.; Ambinakudige, S.; Qin, Y.C.; Li, Y.; Xie, Z.X.; Zhang, L.J.; Gu, H.B. Spatial Accessibility to Hospitals based on Web Mapping API: An Empirical Study in Kaifeng, China. Sustainability 2019, 11, 1160. [CrossRef]

24. Luo, J.; Chen, G.P.; Li, C.; Xia, B.Y.; Sun, X.; Chen, S.Y. Use of an E2SFCA Method to Measure and Analyse Spatial Accessibility to Medical Services for Elderly People in Wuhan, China. Int. J. Environ. Res. Public Health 2018, 15, 1503. [CrossRef] [PubMed]

25. Liu, S.R.; Qin, Y.C.; Xu, Y.N. Inequality and Influencing Factors of Spatial Accessibility of Medical Facilities in Rural Areas of China: A Case Study of Henan Province. Int. J. Environ. Res. Public Health 2019, 16, 1833. [CrossRef] [PubMed]

26. Tao, Y.H.; Shen, Y. Spatial difference of medical facility accessibility and influencing factors: A comparative study of registered and floating populations in Shanghai. Prog. Geogr. 2018, 37, 1075-1085. [CrossRef]

27. Rong, P.J.; Zheng, Z.C.; Kwan, M.P.; Qin, Y.C. Evaluation of the spatial equity of medical facilities based on improved potential model and map service API: A case study in Zhengzhou, China. Appl. Geogr. 2020, 119, 102192. [CrossRef]

28. Zhang, S.Y.; Song, X.Q.; Wei, Y.P.; Deng, W. Spatial Equity of Multilevel Healthcare in the Metropolis of Chengdu, China: A New Assessment Approach. Int. J. Environ. Res. Public Health 2019, 16, 493. [CrossRef] [PubMed]

29. Han, Z.L.; Li, B.; Zhang, K.L. Evaluation and spatial analysis of the equalization of basic public service in urban and rural areas in China. Geogr. Res. 2015, 34, 2035-2048. [CrossRef]

30. Han, C.Y.; Liu, X.Q.; Shen, X.J.; Zhang, L.; Feng, N.N. Evaluating the Spatial Deprivation of Public Transportation Resources in Areas of Rapid Urbanization: Accessibility and Social Equity. Discret. Dyn. Nat. Soc. 2019, 2019, 6890362. [CrossRef]

31. Zhang, D.H.; Zhou, C.S.; Xu, W.W. Spatial-Temporal Characteristics of Primary and Secondary Educational Resources for Relocated Children of Migrant Workers: The Case of Liaoning Province. Complexity 2020, 2020, 7457109. [CrossRef] 
32. He, X.; Yuan, X.D.; Zhang, D.H.; Zhang, R.R.; Li, M.; Zhou, C.S. Delineation of Urban Agglomeration Boundary Based on Multisource Big Data Fusion-A Case Study of Guangdong-Hong Kong-Macao Greater Bay Area(GBA). Remote Sens. 2021, $13,1081$. [CrossRef]

33. Guo, A.D.; Yang, J.; Sun, W.; Xiao, X.M.; Xia, C.J.H.; Jin, C.; Li, X.M. Impact of urban morphology and landscape characteristics on spatiotemporal heterogeneity of land surface temperature. Sustain. Cities Soc. 2020, 63, 102443. [CrossRef]

34. Yang, J.; Yang, Y.X.; Sun, D.Q.; Jin, C.; Xiao, X.M. Influence of urban morphological characteristics on thermal environment. Sustain. Cities Soc. 2021, 72, 103045. [CrossRef]

35. Radke, J.; Mu, L. Spatial decomposition, modeling and mapping service regions to predict access to social programs. Geogr. Inf. Sci. 2000, 6, 105-112. [CrossRef]

36. Luo, W.; Wang, F.H. Measure of spatial accessibility to healthcare in a GIS environment: Synthesis and a case study in Chicago. Environ. Plan. B Plan. Des. 2003, 30, 865-884. [CrossRef] [PubMed]

37. Zhang, D.H.; Zhou, C.S.; Sun, D.Q.; Qian, Y. The influence of the spatial pattern of urban road networks on the quality of business environments: The case of Dalian City. Environ. Dev. Sustain. 2021. [CrossRef]

38. Peeters, D.; Thomas, I. Distance predicting functions and applied location-allocation model. Geogr. Syst. 2000, 2, 167-184. [CrossRef]

39. Chen, C.F.; Zhao, N.; Yue, T.X.; Guo, J.Y. A generalization of inverse distance weighting method via kernel regression and its application to surface modeling. Arab. J. Geosci. 2015, 8, 6623-6633. [CrossRef]

40. Karst, T.G. Evaluation of accessibility impacts of land-use scenarios: The implications of job competition, land-use, and infrastructure developments for the Netherlands. Environ. Plan. B Plan. Des. 2003, 30, 69-87. [CrossRef]

41. Florence, E.S.S.; Fahrul, H.; Ratna, S.D.; Nugroho, P.; Nadya, O. GIS-based approaches on the accessibility of referral hospital using network analysis and the spatial distribution model of the spreading case of COVID-19 in Jakarta, Indonesia. BMC Health Serv. Res. 2020, 20, 1053. [CrossRef]

42. Yang, J.; Guo, A.D.; Li, X.M.; Huang, T. Study of the Impact of a High-Speed Railway Opening on China's Accessibility Pattern and Spatial Equality. Sustainability 2018, 10, 2943. [CrossRef]

43. Jin, S.H.; Yang, J.; Wang, E.X.; Liu, J. The influence of high-speed rail on ice-snow tourism in northeastern China. Tour. Manag. 2020, 78, 104070. [CrossRef]

44. Yang, J.; Bao, Y.J.; Zhang, Y.Q.; Li, X.M.; Ge, Q.S. Impact of Accessibility on Housing Prices in Dalian City of China Based on a Geographically Weighted Regression Model. Chin. Geogr. Sci. 2018, 28, 505-515. [CrossRef]

45. Lukasz, L.; Angelika, J. Spatial Accessibility of Primary Health Care in Rural Areas in Poland. Int. J. Environ. Res. Public Health 2021, 18, 9282. [CrossRef]

46. Zhou, C.S.; Zhang, D.H.; He, X. Transportation Accessibility Evaluation of Educational Institutions Conducting Field Environmental Education Activities in Ecological Protection Areas: A Case Study of Zhuhai City. Sustainability 2021, $13,9392$. [CrossRef]

47. Asare-Akuffo, F.; Twumasi-Boakye, R.; Appiah-Opoku, S.; Sobanjo, J.O. Spatial accessibility to hospital facilities: The case of Kumasi, Ghana. Afr. Geogr. Rev. 2020, 39, 120-133. [CrossRef]

48. Cheng, L.; Yang, M.; Jonas, D.V.; Frank, W. Examining geographical accessibility to multi-tier hospital care services for the elderly: A focus on spatial equity. J. Transp. Health 2020, 19, 100926. [CrossRef]

49. Bauer, J.; Klingelhöfer, D.; Maier, W.; Schwettmann, L.; Groneberg, D.A. Prediction of hospital visits for the general inpatient care using floating catchment area methods: A reconceptualization of spatial accessibility. Int. J. Health Geogr. 2020, 19, 29. [CrossRef]

50. Kim, Y.; Byon, Y.J.; Yeo, H. Enhancing healthcare accessibility measurements using GIS:A case study in Seoul, Korea. PLoS ONE 2018, 13, e0193013.

51. Zhao, P.J.; Li, S.X.; Liu, D. Unequable spatial accessibility to hospitals in developing megacities: New evidence from Beijing. Health Place 2020, 65, 102406. [CrossRef]

52. Zafri, N.M.; Nurullah, M.; Neema, M.N.; Waliullah, M. Spatial accessibility to healthcare facilities in coastal region of Bangladesh. Int. J. Health Plan. Manag. 2021, 36, 643-655. [CrossRef] [PubMed] 